\title{
Deep Dive into Plastic Monomers, Additives, and Processing Aids
}

\section{Journal Article}

\section{Author(s):}

Wiesinger, Helene; Wang, Zhanyun (D); Hellweg, Stefanie (D)

Publication date:

2021-07-06

Permanent link:

https://doi.org/10.3929/ethz-b-000495854

\section{Rights / license:}

Creative Commons Attribution-NonCommercial-NoDerivatives 4.0 International

\section{Originally published in:}

Environmental Science \& Technology 55(13), https://doi.org/10.1021/acs.est.1c00976 


\title{
Deep Dive into Plastic Monomers, Additives, and Processing Aids
}

\author{
Helene Wiesinger,* Zhanyun Wang,* and Stefanie Hellweg
}

Cite This: Environ. Sci. Technol. 2021, 55, 9339-9351

Read Online

ABSTRACT: A variety of chemical substances used in plastic production may be released throughout the entire life cycle of the plastic, posing risks to human health, the environment, and recycling systems. Only a limited number of these substances have been widely studied. We systematically investigate plastic monomers, additives, and processing aids on the global market based on a review of 63 industrial, scientific, and regulatory data sources. In total, we identify more than 10'000 relevant substances and categorize them based on substance types, use patterns, and hazard classifications wherever possible. Over 2'400 substances are identified as substances of potential concern as they meet one or more of the persistence, bioaccumulation, and toxicity criteria in the European Union. Many of these substances are hardly studied

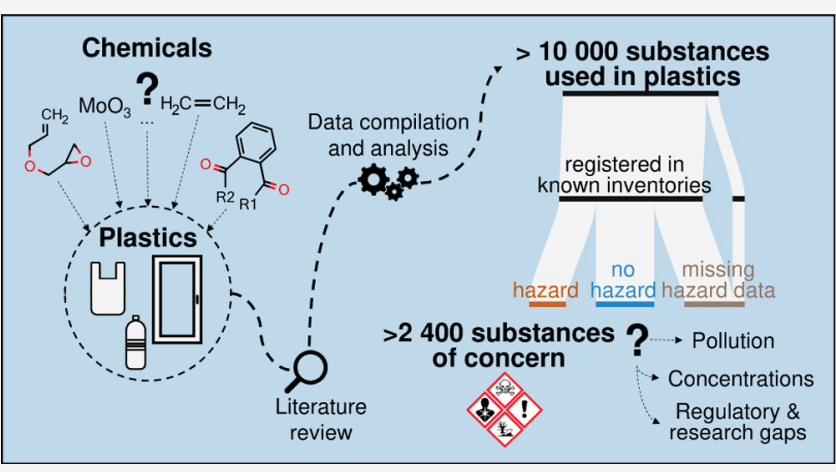
according to SciFinder (266 substances), are not adequately regulated in many parts of the world (1'327 substances), or are even approved for use in food-contact plastics in some jurisdictions (901 substances). Substantial information gaps exist in the public domain, particularly on substance properties and use patterns. To transition to a sustainable circular plastic economy that avoids the use of hazardous chemicals, concerted efforts by all stakeholders are needed, starting by increasing information accessibility.

KEYWORDS: plastic products, plasticizers, plastic pollution, chemical inventory, production volume, substances of concern, circular economy, regulatory status

\section{INTRODUCTION}

Plastics are widely used in various industrial sectors including packaging, construction, automotive, electronics, textiles, household items, and toys, with the current global production reaching over 350 million tonnes per year $(\mathrm{t} / \mathrm{yr}) .{ }^{1}$ These synthetic materials can be molded or shaped and are made of an organic polymer matrix and chemical additives. In their production and processing, a variety of chemical substances are used. ${ }^{2-5}$ The basis of plastics, organic polymers, is made from repeating monomer units. ${ }^{4}$ Additives help to maintain, enhance, and impart specific properties (e.g., antioxidants for maintaining the polymer matrix against oxidative conditions, plasticizers for enhancing flexibility, and flame retardants for imparting fire resistance) ${ }^{6,7}$ Processing aids enable or ease the production or processing of plastics (e.g., polymerization catalysts, solvents, or lubricants) ${ }^{8,9}$ In addition to these intentionally used chemicals, many nonintentionally added substances (NIASs) can also be present in plastics, including byproducts, breakdown products, and contaminants. $^{10,11}$

Thus, plastics contain many substances that are not chemically bound to the polymer matrix, including unreacted monomers, residual processing aids and additives. These substances may be released during the plastic life cycle, resulting in human and environmental exposure. ${ }^{12-20}$ Adverse health effects have been observed for consumers, workers in the plastic production and recycling industries, and communities and ecosystems that are near production and recycling facilities. ${ }^{21-25}$ In addition, substances present in plastics may also hamper the transition to a circular economy, by impairing recycling processes and the safety and quality of recycled materials. ${ }^{26-30}$

Despite growing scientific evidence and public concern, current research and regulatory actions have focused on a limited selection of substances, mostly well-known hazardous ones $^{31-33}$ or those commonly known for their presence in plastics. $^{34,35}$ This phenomenon is partially because information on plastic monomers, additives, and processing aids is limited and scattered in the public domain. A recent review looked into substances used in plastic packaging and identified more than 4'000 potentially relevant substances, more than half lacked hazard classifications and a majority lacked detailed use descriptions. ${ }^{13}$ Currently, such an extensive assessment is lacking for plastics used in other industrial sectors. While recent development of nontarget analysis using high-resolution mass spectrometry provides new possibilities to look into a larger set of substances in plastics, the wide application of such techniques

Received: February 9, 2021

Revised: $\quad$ May 31, 2021

Accepted: May 31, 2021

Published: June 22, 2021

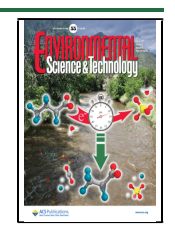




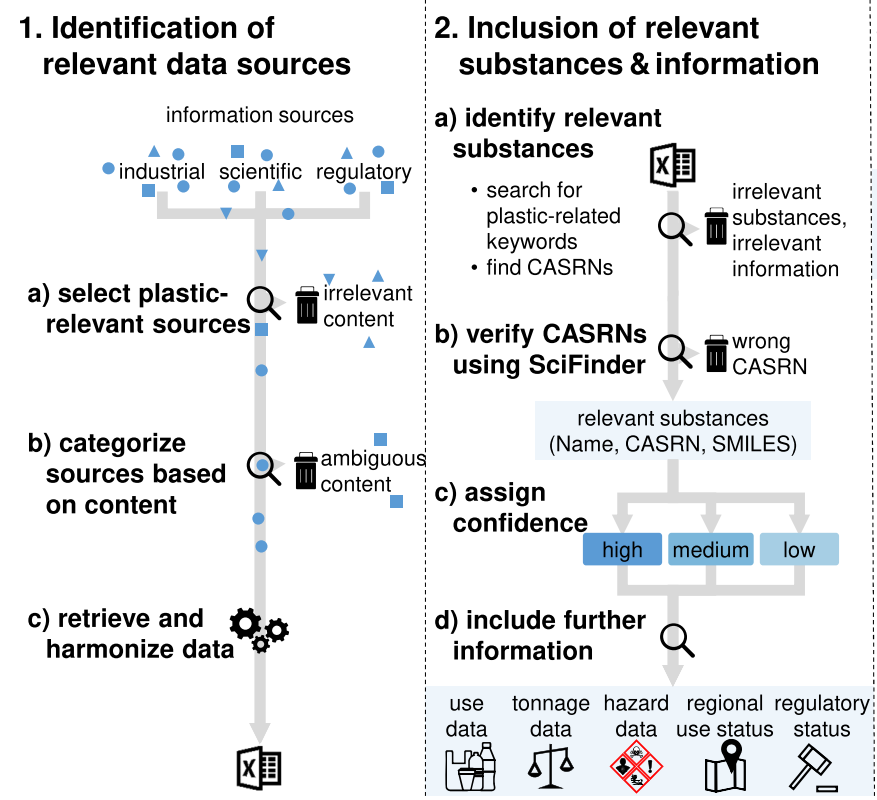

\section{Categorization of substance types \& use patterns}

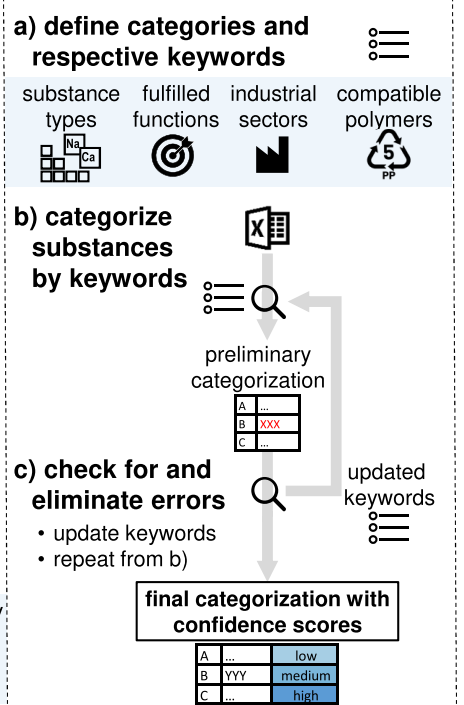

4. Identification of substances of (potential) concern

a) identify substances with concerning properties
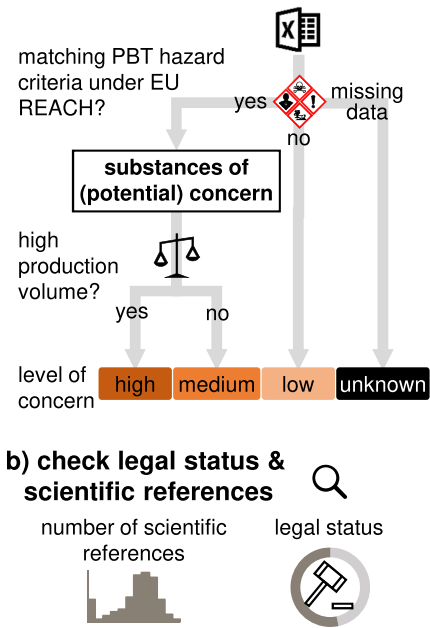

Figure 1. Schematic overview of the workflow in this study. CASRNs = Chemical Abstracts Service Registry Numbers; SMILES = simplified molecular-input line-entry system; REACH = Regulation on Registration, Evaluation, Authorisation and Restriction of Chemicals; PBT = persistent, bioaccumulative and toxic; EU = European Union.

is still limited, in part because of challenges in interpreting the overwhelming amount of data generated. ${ }^{14,36-41}$ Some researchers have suggested the use of so-called suspect lists to enhance substance identification. ${ }^{36,42}$

Hence, to inform future studies and action on substances present in plastics, this study systematically collects and analyzes publicly available information on intentionally added substances (i.e., monomers, additives, and processing aids) in plastics of all industrial sectors. In particular, this study investigates chemical identities, uses patterns (functions, compatible polymer types, industrial sectors of use, geographical distribution, and production volumes), and reported hazard classifications. Furthermore, based on reported hazard classifications, production volumes, and regulatory status, substances of potential concern are identified. Major lessons learned, including critical data and knowledge gaps, are then highlighted, followed by an outlook on possible ways forward.

\section{METHODS}

This study was conducted in four steps: (1) identification of relevant data sources, (2) inclusion of relevant substances and information, (3) categorization of substance types and use patterns, and (4) identification of substances of potential concern (Figure 1). Individual steps are summarized in the following subsections, and additional details are provided in the Supporting Information files, Supporting Information S1 and Supporting Information S2.

2.1. Identification of Relevant Data Sources. Relevant data sources were identified from (1) target scientific literature, ${ }^{13,43,44}$ (2) a bibliographic search of the keywords "plastic additives", "plastic", and "polymer" in the Web of Science, Scopus, and Google Scholar, and (3) a search of manufacturers', distributors', and regulators' websites and databases. In the bibliographic search, books and review articles were manually selected, and individual research articles were excluded due to time and resource constraints. Sources were excluded that deal solely with polymers but are irrelevant for plastics; similarly, sources that deal exclusively with NIASs were excluded, as this study deals with substances intentionally added to plastics. The internet search focused on sources that include explicit use information.

In total, 190 relevant sources were identified and categorized based on information content, data accessibility, and source type (i.e., regulatory, scientific, and industrial), see Sheet $S 1$ in Supporting Information S1. Among them, 63 sources provided readily accessible information and were further processed; the rest were not used, as they referred only to general groups of substances (e.g., phenolic antioxidants and fatty acid esters) or were not machine-processable (e.g., information embedded in unstructured texts; only in print versions). Data treatment and retrieval processes varied for the 63 sources; for details, see Sheet S1 in Supporting Information S1.

2.2. Inclusion of Relevant Substances and Information. Plastic monomers, additives, or processing aids were identified by searching for plastic-related keywords in the respective use descriptions of individual substances (for details, see Sheet S1 in Supporting Information S1). Some NIASs may also be included where the keywords appeared in their use descriptions, but no specific efforts were made to distinguish them. Only substances for which the assigned Chemical Abstract Service Registry Numbers (CASRNs) were provided in the sources were included for further analysis, and the rest were excluded, due to the high workload and uncertainties associated with finding their corresponding CASRNs.

Identified CASRNs were verified using the check-digit method (Section S1.2 in Supporting Information S2). ${ }^{45,46}$ Furthermore, the status of identified CASRNs and their connected CASRNs assigned by the Chemical Abstracts Service (i.e., "active", "deleted", or "alternate") were retrieved from SciFinder. ${ }^{46}$

Confidence in identifying target substances was assessed using a weighted scoring approach. First, individual sources were scored based on their information origin and outlet control, as well as the identification method used and data processing needs 
in this study (Table S2 in Supporting Information S2). Then, substance confidence scores were assigned by taking the highest score of their individual sources; for those substances that were identified through multiple first-hand information sources, a combined confidence score was calculated (Section S1.2.3 in Supporting Information S2).

Use descriptions (including information on functions, compatible polymer types, and relevant industrial sectors) were retrieved from the original sources. Additional information was retrieved for the identified substances using all CASRNs (including deleted and alternate ones), namely, structural identifiers [that is, CAS names, molecular formula, and simplified molecular-input line-entry system (SMILES) entries], reported hazard classifications, production volumes, regional use status, and regulatory status in specific regions. Details on the retrieval of information can be found in Sheet S2 in Supporting Information S1.

CAS names and molecular formulas were retrieved from SciFinder. ${ }^{46}$ SMILES entries representing molecular structures were retrieved from the CompTox Chemicals Dashboard. ${ }^{47}$

Two types of reported hazard classifications were retrieved (details in Sheet S2 in Supporting Information S1): (1) those that were harmonized by regulatory agencies, hereafter referred to as "regulator-harmonized", and (2) those that were reported by individual companies to regulators, or "company-reported". Regulator-harmonized hazard classifications were retrieved from the International Agency for Research on Cancer (IARC) Classified Agents List, ${ }^{48}$ the Australian Hazardous Chemicals Information System (HCIS), ${ }^{49}$ the Japanese GHS classification results, $^{50}$ the European Union Classification and Labelling Inventory (EU C\&L Inventory-Harmonized C\&L), ${ }^{51}$ and the concluded assessments under the EU Registration, Evaluation, Authorisation and Restriction of Chemicals (REACH) regulation. Assessments under REACH include the authorization list, ${ }^{52}$ the candidate list of substances of very high concern (SVHC) list, ${ }^{53}$ the persistent, bioaccumulative and toxic substances (PBT) assessment list, ${ }^{54}$ and the endocrine disruptor (EDC) assessment list. ${ }^{55}$ Company-reported hazard classifications were retrieved from the EU REACH (REACH Registration C\&L Data) and C\&L (CLP Notification C\&L Data) registration dossiers, ${ }^{56}$ and the Organisation for Economic Co-operation and Development (OECD) eChemPortal. ${ }^{57}$ No additional hazard classification was conducted in this study. Hazard data from different sources were checked for consistency.

Production volumes were retrieved from the OECD high production volume chemical (HPVC) list, ${ }^{58}$ the United States Environmental Protection Agency (USEPA) Chemical Data Reporting (CDR) program, ${ }^{59}$ the EU REACH registration dossiers, ${ }^{60}$ and the Substances in Preparations in the Nordic countries (SPIN) database ${ }^{61}$ (Sheet S2 in Supporting Information S1). Substances were labeled HPVCs when their total reported production volumes in the EU (or in the Nordic countries if the EU production volumes were not available) and the US surpassed $1000 \mathrm{t} / \mathrm{yr}$ or when they were listed on the OECD HPVC list. The retrieved production volumes comprise the total annual amounts produced in a region for all uses, not just the use in plastics.

The regional use status was assessed by checking the registration status of identified substances in individual national and regional chemical inventories around the world (Sheet S2 in Supporting Information S1 and Figure S5 in Supporting Information S2). ${ }^{62}$
Regulatory status in specific regions was assessed by checking the presence of identified substances on various regulatory lists (Sheet S2 in Supporting Information S1). These include lists of chemicals regulated under the Stockholm Convention, the Montreal Protocol, and the Rotterdam Convention, as well as the regulatory lists in the EU, Japan, Republic of Korea, and the US (Figure S7 in Supporting Information S2). Also, the regulatory positive lists of substances allowed in food-contact plastics in the EU, US, and Japan were included. In some cases, groups of chemicals [for example, perfluorooctanoic acid (PFOA), its salts, and related compounds; cadmium compounds] are regulated without explicit referencing all relevant substances; such cases required manual searches for relevant substance names, SMILES, or molecular formulas.

2.3. Categorization of Substance Types and Use Patterns. Using keyword searches, identified substances were categorized according to their substance types (e.g., organometallic or organohalogen compounds) and use patterns. These included functions (e.g., colorants and fillers), compatible polymer types (e.g., polyethylene or PE, polyvinyl chloride or PVC), and industrial sectors of use (e.g., automotive, packaging, and food-contact plastics).

For substance types, categorization was made by searching for specific chemical elements in substance names, SMILES, or molecular formulas (Sheet S6 in Supporting Information S1). Furthermore, specific keywords were used to identify UVCBs (substances of unknown or variable composition, complex reaction products, or biological materials), mixtures, and polymers. $^{62}$

For use patterns, an iterative approach was employed, consisting of three steps: (a) defining initial categories and associated keywords, (b) categorizing, and (c) checking errors and updating keywords, where steps (b) and (c) were repeated until the observed error frequencies dropped to below $10 \%$. The final set of categories and the corresponding keywords can be found in Sheets S3-S6 in Supporting Information S1.

(a) Initial categories and associated keywords were defined for functions (using definitions in industrial handbooks), ${ }^{6,8,9,63}$ compatible polymer types, and industrial sectors of use (based on recent plastic material flow analyses). 1,64,65 Keywords included synonyms (e.g., "HDPE" for high-density polyethylene), hyponyms (e.g., "fridge" for electronics and "milk bottle" for food packaging), and hypernyms [for example, "polyolefin" for (high- and low-density) polyethylene]. These were refined by manually including relevant frequently used terms in the use descriptions of identified substances (Section S1.3 in Supporting Information S2).

(b) The categorization was conducted by carrying out regular expression searches for keywords in the use descriptions of identified substances.

(c) A random selection of the categorization results was manually checked for errors (Sheet S7 in Supporting Information S1). Error-prone keywords were deleted or improved (e.g., using more advanced regular expressions such as "lookbehind" and "lookahead" expressions-the initial keyword "PE" was changed to "PE(?!T)" to exclusively match "PE" without matching "PET" as well). Some errors may remain, mainly due to ambiguities in the original use descriptions provided in individual sources (e.g., "used in paint" without details for which functions). 


\section{A - Overview over substances}

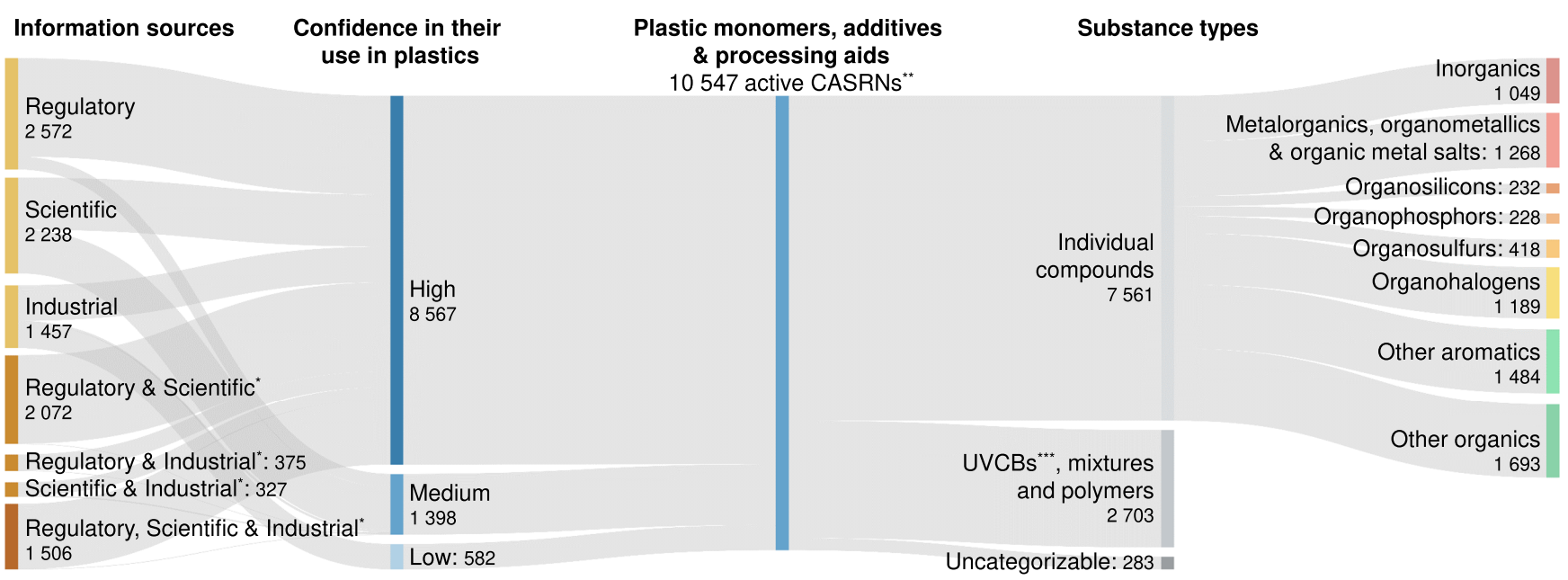

* Substances are found in sources of all mentioned types

** These active CASRNs are associated with 24901 deleted CASRNs and 22 alternate CASRNs

"** Substances of unknown or variable composition, complex reaction products, or biological materials

\section{B - Data availability}

number of the substances for which individual types of data are available

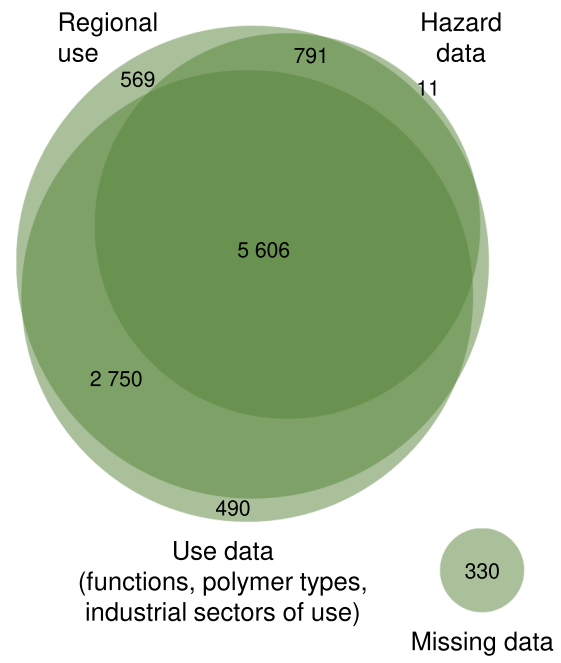

C - Function category

number of the substances that fall under individual function categories

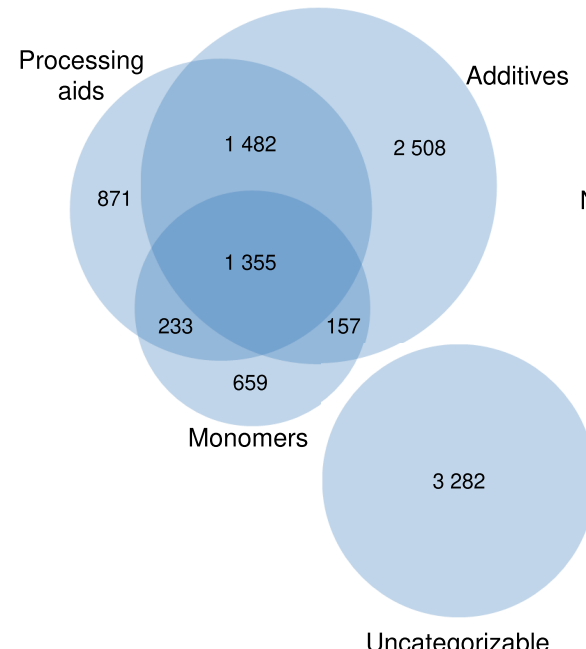

\section{D - Regional Use}

number of the substances that are registered in individual regions or countries

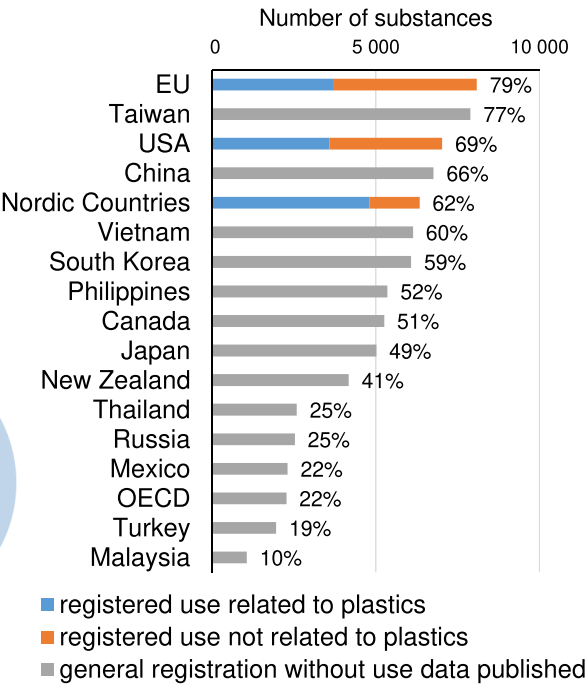

Figure 2. Overview of the substances that are (potentially) used as plastic monomers, additives, and/or processing aids. Part (A) illustrates the distribution of the substances identified in terms of information sources, assigned confidence scores of their use in plastics, and substance types. Part (B) shows examples of data availability in different areas. Part (C) depicts numbers of the substances falling under the broader function categories "monomers", "additives", "processing aids", and "uncategorizable". Part (D) exhibits numbers of the substances registered for production and/or use in different regions and countries; for those national or regional inventories with publicly accessible information on uses, the reported uses are analyzed whether they are linked to plastics (as defined in Sheet S1 in Supporting Information S1).

Confidence scores were assigned to individual categorizations based on the information origin and outlet control of individual sources, nature of the keywords (i.e., synonym, hyponym, and hypernym), and observed error frequency (Table S4 in Supporting Information S2).

\subsection{Identification of Substances of Potential Concern.}

Substances of potential concern were identified and assigned a level of potential concern using a simplified two-step approach, based on hazard classifications and production volumes as surrogate reflecting potentials for causing adverse effects and exposure, respectively.
In the first step, substances that fulfill one or more of the following hazard criteria under EU REACH were identified as substances of potential concern: $\mathrm{PBT} /$ very persistent and very bioaccumulative ( $\mathrm{vPvB})$, carcinogenicity $(\mathrm{C})$, mutagenicity $(\mathrm{M})$, reproductive toxicity (R), endocrine disruption (ED), specific target organ toxicity upon repeated exposure ( STOT-RE), and chronic aquatic toxicity (AqTox). Detailed criteria for the different hazard classifications can be found in Table S5 in Supporting Information S2. Substances with insufficient hazard information or without any information at all in the considered regulatory databases were categorized as "unknown", whereas those with full hazard information but that 


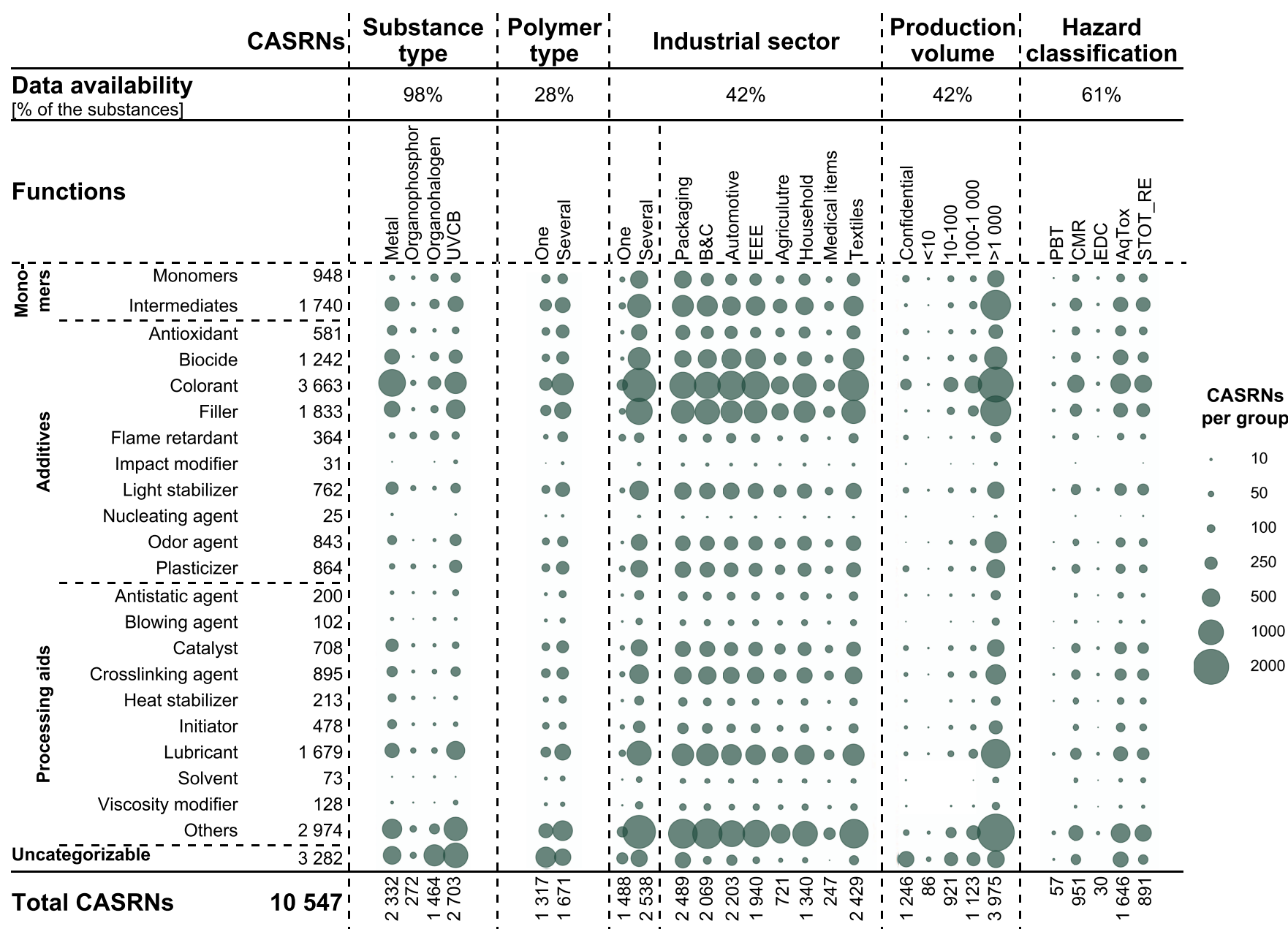

Figure 3. Overview of the substance types, compatible polymer types, industrial sector of use, production volumes, and reported hazard classifications of the identified substances according to their function. The production volume is in tonnes per year $(\mathrm{t} / \mathrm{yr})$ and represents all uses not just the fraction used in plastics. Data availability is the percentage of substances for which this type of data is available. Intermediates are grouped with monomers, as they are commonly mentioned together. "Others" is an umbrella for many small, ambiguous, or only remotely plastic-related functions. UVCBs $=$ substances of unknown or variable composition, complex reaction products, or biological materials, and simple mixtures, or polymers, $\mathrm{B} \& \mathrm{C}=$ building and construction, $\mathrm{EEE}=$ electrical and electronic equipment, $\mathrm{PBT}=$ persistence, bioaccumulation, and toxicity, $\mathrm{CMR}=$ carcinogenicity, mutagenicity, or reproductive toxicity, EDC = endocrine-disrupting chemicals, AqTox = chronic aquatic toxicity, and STOT_RE = specific target organ toxicity upon repeated exposure.

did not meet any of the considered hazard criteria were categorized as the "low level of concern". In the second step, depending on production volumes, identified substances of potential concern were either considered the "medium level of concern" ( $\left.<1^{\prime} 000 \mathrm{t} / \mathrm{yr}\right)$ or "high level of concern" (>1'000 t/yr).

Identified substances of potential concern were further assessed concerning their regulatory status (Section 2.2) and the number of scientific references reported in SciFinder. ${ }^{46}$

2.5. Quality Assurance and Quality Control. As stated above, data quality was assured using several procedures. For substance identification, quality assurance and quality control (QA/QC) included assigning confidence scores to the sources and substances (Sheet S1 in Supporting Information S1), verifying the check digit of CASRNs, ${ }^{45}$ and checking the CASRN status in SciFinder (Section 2.2). For substance type and use pattern categorization, QA/QC included iterative keyword optimization (Section 2.3) and assigning confidence scores to each categorization. For the identification of substances of potential concern, QA/QC included a hazard data consistency check (Figure S6 in Supporting Information S2) and manually double-checking the regulatory status. The remaining uncertainties are mostly due to misreported or missing information and are qualitatively discussed in Section 4.

\section{RESULTS}

3.1. Overview of Plastic Monomers, Additives, and Processing Aids. In total, substances with 10'547 unique active CASRNs are identified, mostly with high confidence in their use as plastic monomers, additives, and processing aids (Figure 2A, Sheet S8 in Supporting Information S1). These active CASRNs are associated with another 24'901 deleted CASRNs (i.e., replaced by the active CASRNs) and 22 alternate CASRNs (i.e., CASRNs in parallel use to the active ones). A number of these deleted or alternate CASRNs are still being used in different information sources.

All source types (scientific, regulatory, and industrial) are important for substance identification (Figure 2A). A total of 4'280 CASRNs have been reported in more than one type of source, whereas over 6'267 CASRNs have only been reported in one type of source (note that they can occur in several sources, but all of these belong to the same source type). 
Table 1. Overview of Substances of Potential Concern Used as Plastic Monomers, Additives, or Processing Aids

\begin{tabular}{|c|c|c|c|c|c|c|c|c|c|c|c|c|c|c|c|}
\hline \multirow{3}{*}{$\begin{array}{l}\text { Hazard } \\
\text { Type }^{\mathbf{a}}\end{array}$} & \multicolumn{3}{|c|}{ Number of substances } & \multicolumn{4}{|c|}{ HPVCs $^{\mathrm{b}}$} & \multicolumn{4}{|c|}{ Not regulated $^{\mathrm{c}}$} & \multicolumn{4}{|c|}{$\begin{array}{l}\text { Without any scientific ref- } \\
\text { erences in SciFinder }\end{array}$} \\
\hline & \multirow{2}{*}{$\begin{array}{c}\text { Total } \\
\# \\
\end{array}$} & \multirow{2}{*}{$\begin{array}{c}\text { Regulator- } \\
\text { harmonized } \\
\text { hazard } \\
\text { classifications } \\
\#\end{array}$} & \multirow{2}{*}{$\begin{array}{c}\text { Company- } \\
\text { reported } \\
\text { hazard } \\
\text { classifications } \\
\#\end{array}$} & \multicolumn{2}{|c|}{ Total } & \multicolumn{2}{|c|}{$\begin{array}{c}\text { Regulator- } \\
\text { harmonized } \\
\text { hazard } \\
\text { classifications }\end{array}$} & \multicolumn{2}{|c|}{ Total } & \multicolumn{2}{|c|}{$\begin{array}{c}\text { Regulator- } \\
\text { harmonized } \\
\text { hazard } \\
\text { classifications }\end{array}$} & \multicolumn{2}{|c|}{ Total } & \multicolumn{2}{|c|}{$\begin{array}{l}\text { Regulator- } \\
\text { harmonized } \\
\text { hazard } \\
\text { classifications }\end{array}$} \\
\hline & & & & \# & $\%^{\mathrm{d}}$ & \# & $\%^{\mathrm{e}}$ & \# & $\%^{\mathrm{d}}$ & \# & $\% \mathrm{e}^{\mathrm{e}}$ & \# & $\%^{\mathrm{d}}$ & \# & $\%^{\mathrm{e}}$ \\
\hline$P B T / v P v B$ & 57 & 57 & - & 26 & 45.6 & 26 & 45.6 & 10 & 17.5 & 10 & 17.5 & 10 & 17.5 & 10 & 17.5 \\
\hline$C M R$ & 951 & 603 & 856 & 501 & 52.7 & 311 & 51.6 & 350 & 36.8 & 143 & 23.7 & 91 & 9.6 & 68 & 11.3 \\
\hline$E D C$ & 30 & 30 & - & 17 & 56.7 & 17 & 56.7 & 3 & 10.0 & 3 & 10.0 & 3 & 10.0 & 3 & 10.0 \\
\hline AqTox & 1646 & 554 & 1640 & 754 & 45.8 & 318 & 57.4 & 897 & 54.5 & 216 & 39.0 & 188 & 11.4 & 18 & 3.2 \\
\hline STOT_RE & 891 & 617 & 783 & 562 & 63.1 & 387 & 62.7 & 331 & 37.1 & 175 & 28.4 & 57 & 6.4 & 23 & 3.7 \\
\hline $\begin{array}{l}\text { Any of the } \\
\text { above }\end{array}$ & 2486 & 1260 & 2360 & 1254 & 50.4 & 739 & 58.9 & 1327 & 53.4 & 461 & 36.6 & 266 & 10.7 & 90 & 7.1 \\
\hline
\end{tabular}

$a_{\mathrm{vPvB}}=$ very persistent and very bioaccumulative, $\mathrm{PBT}=$ persistence, bioaccumulation, and toxicity, $\mathrm{CMR}=$ carcinogenicity, mutagenicity, or reproductive toxicity, EDC = endocrine-disrupting chemicals, AqTox = chronic aquatic toxicity, and STOT_RE = specific target organ toxicity upon repeated exposure. ${ }^{b} \mathrm{HPVC}=$ high production volume chemical, that is, production volume larger than 1'000 $\mathrm{t} / \mathrm{yr}$. Only their total production volumes for all uses (including ones other than in plastics) are available. ${ }^{c}$ Under any of the regulations considered in this study (Sheet S2 in Supporting Information S1). ${ }^{d}$ The percentage of the total number of chemicals within that hazard group. ${ }^{e}$ The percentage of the number of chemicals from regulator-harmonized hazard data within that hazard group.

More than $25 \%$ of the substances (2'703 CASRNs) are UVCBs, mixtures, and polymers, whereas almost all the rest (7'561) are individual compounds (Figure 2A). The majority of individual compounds are organic ones (6'513), including 232 organosilicons, 228 organophosphorus, 418 organosulfurs, 1'189 organohalogens, and 1'268 organic metal(loid) salts, metalorganics, or organometallics. For $2.5 \%$ of the identified substances (283), their substance types are currently uncategorizable (Figures 2A, 3-data availability) because they are registered by their trade or trivial names [for example, Ixol $M$ 125 (CASRN 86675-46-9), C.I. Pigment Yellow 157 (CASRN $68610-24-2)]$ and lack other identifiers such as SMILES or molecular formulas that can reflect their chemical structures.

Information availability varies considerably among the 10'547 substances, with most substances having information on their use or registration status in specific regions (>90\%), followed by production volumes (70\%), functions (69\%), and any reported hazard classifications $(61 \%)$. For the rest, substantial information gaps persist: industrial sectors of use (40\%), regulatorharmonized hazard classifications (22\%), and compatible polymer types $(16 \%)$. Around $3 \%$ of the substances lack any information other than their chemical names and CASRNs (Figure 2B).

Overall, $55 \%$ of the substances identified are categorized as plastics additives, $39 \%$ as processing aids, and $24 \%$ as monomers, with significant overlaps between these three categories. In addition, due to a lack of information, $30 \%$ of the substances remain uncategorizable regarding their functions (Figure 2C).

Overall, more than $90 \%$ of the substances are registered for production and use in one or more of the regions or countries considered; about 55\% are registered in more than 9 countries and regions, compared to $7 \%$ that are region/country-specific. In individual countries or regions, $20-80 \%$ of the substances are registered (Figure 2D). Inventories from the US, EU, and Nordic countries (Denmark, Finland, Norway, and Sweden) contain publicly accessible use information; our analysis shows that many of the identified substances are seemingly registered for uses without direct linkages to plastics in these inventories (US: 50\%, EU: 50\%, and Nordic countries: 20\%; Figure 2D). Reasons for this reporting difference may be actual uses for other purposes, ambiguity in the reporting, or under- or misreporting. For example, tetrabromobisphenol A bis(dibromopropyl ether) (TBBPA-BDBPE; CASRN 21850-44-2; a flame retardant) and Tinuvin 765 (CASRN 41556-26-7; a light stabilizer) are registered in both the SPIN and REACH databases, but their use in plastics is reported in only one (Tinuvin 765 in the SPIN database and TBBPA-BDBPE in the REACH database).

3.2. Overview of the Use Patterns. Functions are identified for a majority of the substances (7'265 CASRNs, $69 \%$ ), in comparison to the much lower identification of information on compatible polymer types (3'002 CASRNs, $28 \%)$ and industrial sectors of use (4'383 CASRNs, 42\%). Typically, substances can fulfill several functions (on average, two to three functions), be used in multiple polymer types (particularly in similar polymer types such as polyolefins), and be used in multiple industrial sectors (Figure 3). A total of 2'263 CASRNs are reported for use in the following applications with high exposure potential: 2'109 in food-contact applications, 522 in toys, and 247 in medical items including masks (Sheet S8 in Supporting Information S1 under the "industrial_sector").

Based on the production volumes reported in the EU, the US, and the Nordic countries and the OECD HPVC list, about 4'000 substances are HPVCs (i.e., >1'000 t/yr; Figure 3); however, these represent their total production volumes for all uses and not just the fractions used in plastics. If production volumes in other regions were available, more substances might be identified as HPVCs. Furthermore, the production volumes of many substances have been reported as "confidential"; their share was the largest for antioxidants (10\%), flame retardants (11\%), and uncategorizable substances (12\%).

3.3. Substances of Potential Concern and Their Regulatory Status. In total, reported hazard classifications 
are available for about 6'400 substances (61\%), whereas about 4'100 substances (39\%) lack any reported hazard classifications in the considered regulatory databases (unknown level of concern). Most substances with unknown levels of concern lack information about their functions (Figure 2B), are not HPVCs in the EU or the US or in the OECD countries, and belong to UVCBs, mixtures, and polymers (Figure S19 in Supporting Information S2).

In total, 3'950 substances (37\%) do not meet any of the considered hazard criteria, while their hazard classifications are available; these are designated as substances of a low level of concern. Another 2'486 substances (24\%) meet one or more of the hazard criteria considered and are identified as substances of potential concern; among them, 1'254 substances (12\%) are also HPVCs and thus of a high level of concern. The remaining 1'232 substances $(12 \%)$ are of a medium level of concern.

An overview of all substances of potential concern is provided in Table 1, and the entire substance list is provided in Sheet $S 9$ in Supporting Information S1. In short, 22 substances are PBT and another 35 are $\mathrm{vPvB}$ substances. A total of 2'368 substances show toxicity of concern, including 951 CMR toxicants, 30 EDCs, 1'646 substances that can cause chronic aquatic toxicity, and 891 substances that may cause specific target organ toxicity upon repeated exposure.

Around 53\% of the substances of potential concern are not subject to any sort of management measures under one or more of the regulations considered in this study (Table 1). Five percent (136 CASRNs) of the substances of potential concern are regulated under the Stockholm Convention, the Rotterdam Convention, or the Montreal protocol. Additionally, 960 of the substances of potential concern are subject to national/regional restrictions (EU: 135; Republic of Korea: 46; and Japan: 16), authorizations (EU: 53; Republic of Korea: 362; and Japan: 15), or prohibitions in specific areas (EU, toys: 440 and EU, electronic waste: 102). Surprisingly, despite having highly problematic hazardous properties, 901 substances of concern also appear on the regulatory positive lists for use in foodcontact plastics (EU: 225; Japan: 568; and US: 667; see columns under "Regulation-Food-contact positive lists" in Sheet S9 in Supporting Information S1).

The number of scientific references that are linked in SciFinder varies greatly per substance (range $=0-1^{\prime} 086^{\prime} 797$ and median = 1'410; see Figures S16 and S24 in Supporting Information S2). Around $10 \%$ of the identified substances of potential concern lack any scientific references in SciFinder, indicating that they may have been poorly studied (Table 1), of these $10 \%$ most are UVCBs, mixtures, and polymers.

\section{DISCUSSION}

4.1. Numbers of Plastic Monomers, Additives, and Processing Aids on the Market. This study has identified over 10'000 CASRNs that are or may potentially be used as plastic monomers, additives, and processing aids. This number is much higher than previous studies because of the broader scope, whereas earlier studies have focused on plastic packaging (4'000 substances) $)^{13}$ and plastic additives with registered tonnages above $100 \mathrm{t} / \mathrm{yr}$ in the EU (400 substances). ${ }^{12}$ Even so, these $10^{\prime} 000$ identified substances might still be an underestimate of the total number of substances present in plastics, mainly due to the following three clusters of reasons:

I There is a general lack of transparency regarding substances present in plastics. ${ }^{66,67}$ Existing practices of national/regional chemical inventories provide limited help on this matter, due to (1) limited public accessibility of production and use information (e.g., only three of the 21 investigated inventories made use information public; much of the information reported in these three inventories is claimed to be "confidential business information") and (2) incompleteness (e.g., reduced reporting requirements for low production volume or "non-hazardous" chemicals ${ }^{62}$ ). Currently, several initiatives targeting better communication of information on chemicals in products along supply chains have been initiated, for example, the EU Sustainable Product Policy Initiative, ${ }^{67,68}$ the Substances of Concern In articles or Products database (SCIP database) hosted by the European Chemicals Agency (ECHA), ${ }^{69}$ and the HolyGrail Project led by $P \& G$ (under the New Plastics Economy program of the Ellen MacArthur Foundation). ${ }^{70}$ However, their effective implementation is currently hindered by factors such as (claims of) complex supply chains, diverging interests and technical capacities of actors within supply chains, and data storage and transfer issues. $^{71,72}$

II Not all data in the public domain are readily machineaccessible and processable; in this study, substances for which the assigned CASRNs are not provided are excluded from the analysis, including ions for ionizable substances or structural isomers (see Section 2.2). This is largely due to a combination of the following reasons: (1) the wide use of nonmachine-readable data formats; (2) current limitations in reporting all relevant substances, including the common use of ambiguous trivial names and group names such as phenolic antioxidants without specifying relevant substances, the wide use of different names for the same substances, the underuse of unique identifiers such as assigned CASRNs, SMILES, and

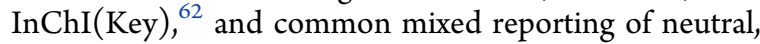
ionized substances, isotopologues, and other isomers using the same identifiers such as CASRNs and chemical names; and (3) a lack of standardized terminology for use patterns across jurisdictions. Concerted efforts to address these problems are necessary to improve, harmonize, and foster nonambiguous reporting of substance identities and use patterns by all stakeholders across the world, building on existing initiatives. ${ }^{3,73-76}$ In addition, advances in information technologies (such as optical character recognition, natural language processing, and cheminformatics tools) to unambiguously recognize different types of chemical identifiers in the text and convert between them may help collect information that currently requires manual processing. ${ }^{77-81}$

III Besides the intentionally added substances considered in this study, also NIASs are highly relevant for plastics because (1) they have been frequently reported in measurements, (2) plastics in many applications are prone to contamination from production, processing, and use, and (3) substance transformation is an integral part of fulfilling specific functions (e.g., formation of quinones from oxidization of phenolic antioxidants). ${ }^{10,41,82-84}$ However, NIASs are not yet comprehensively understood, their identification remains challenging, not least because of a dearth of clarity on plastic compositions and conditions during production and use, and analytical difficulties of unequivocally identifying substances at low 
concentrations remain. ${ }^{10,11,41}$ To improve NIAS identification and quantification, measures such as increasing product transparency through company reporting, obligatory provision of analytical standards, and standardization of sample treatment, separation, and data treatment procedures may be taken. ${ }^{41}$

Meanwhile, for the $10^{\prime} 000$ substances identified here, some uncertainties may remain regarding their use in plastics and their commercial relevance despite several measures for QA. For example, the keyword search in substance identification (Section 2.2) might have yielded substances that are relevant for polymers in uses other than plastics (e.g., polymeric adhesives) or substances used for plastic-related functions but appearing in other materials (e.g., flame retardants in fabrics and plasticizers in concrete formulations). In addition, in the analysis of regional registrations and production volumes (Section 2.2), the current commercial status is not fully covered, as some substances may no longer be in use or might only be used in materials other than plastics (see the next subsection).

4.2. Interpretation of Use Patterns and Their Uncertainties. In line with earlier research, many of the substances identified in this study can be used for different functions in multiple polymer types and industrial sectors. ${ }^{12,13}$ Regarding substances in food-contact applications, a comparison with the recently compiled database of intentionally added food-contact chemicals (FCCdb) showed that despite identifying fewer substances, this study has a good overlap with the FCCdb (this study: 2'109 CASRNs; FCCdb: 11'609 CASRNs; overlapping substances identified by both: 2'026 CASRNs). ${ }^{85}$

The results regarding use patterns (Section 3.2, especially Figure 3) need to be interpreted with caution, as only the number of substances potentially used for different functions (dominated by 3'663 colorants and 1'833 fillers) and the total production volume for all uses (including uses for other functions and in other materials) is presented. A recent market study based on global production volumes shows a different picture that plasticizers, flame retardants, and heat stabilizers dominate the plastic additive market. ${ }^{86,87}$ In addition, solid use data remain lacking for many of the identified substances, especially concerning relevant industrial sectors (missing for $58 \%$ of the substances) and compatible polymer types (missing for $72 \%$ ). Furthermore, uncertainties may be expected for some of the identified uses for the following reasons:

I Reported uses may be incomplete, outdated, or inaccurate. For example, diethyl phthalate (DEP, CASRN 84-66-2) is still frequently reported as a plasticizer in the scientific literature, ${ }^{33,88-90}$ while the industry has reported phase-out of its use as a plasticizer (it is now primarily used as a solvent in cosmetics and other personal care products). ${ }^{91}$ Thus, DEP may be relevant for legacy plastic products and recycled plastics, but not for new virgin plastics. Minimizing such uncertainties requires not just gathering more information from different sources but rather more stringent monitoring of industrial activities and comprehensive QC of existing data (including verifying and updating information sources on a regular basis).

II Some of the keywords used in the identification process in this study may still be incomprehensive or inaccurate, despite efforts to eliminate errors using an iterative learning approach (Section 2.5). This is because a simple keyword search cannot take the whole context into account, cannot distinguish ambiguous terms, and requires large manual efforts to include infrequent keywords. An example of the lack of context sensitivity is benzo $[a]$ pyrene (CASRN 50-32-8). It was first incorrectly identified as a cross-linking agent, a filler, and a lubricant; a closer look revealed that it was reported as a contaminant or byproduct in substances fulfilling these functions. To more accurately categorize use patterns, future efforts need to be made both on developing advanced search algorithms (e.g., using semantic searches and natural language processing) and on standardizing use descriptors. $3,94-96,79,80,92$

III Some important factors concerning use reporting (such as registrants' knowledge on the topic, information processing before reporting, and potential ulterior motives influencing reporting) could not be taken into account. For example, ulterior motives may play a role in the comprehensiveness and accuracy of reporting (such as missed or wrong reporting of risk-related information and exaggeration of the number of applicable uses). ${ }^{93,94}$

\subsection{Substances of Potential Concern and Associated} Uncertainties. More than 2'400 substances of potential concern used in plastics are identified in this study; it may well still be an underestimate of the number of substances of concern, as it is only based on reported hazard classification. For example, many more substances than considered in this study may be persistent and/or bioaccumulative, as only the substances with the PBT assessment outcome of fulfilling (or not fulfilling) all PBT or both $\mathrm{vPvB}$ criteria were separately listed in the REACH PBT assessment list and considered in this study. ${ }^{95}$ Thus, substances that are registered under REACH fulfilling the $\mathrm{P}$ and/or B criteria are not identified in this study, due to time and resource constraints to individually check their $\mathrm{REACH}$ registration dossiers.

Surprisingly, about 350 substances of potential concern appear on both negative (e.g., authorization requested for specific uses and bans in certain applications) and positive (i.e., approval for use in food-contact plastics) regulatory lists. For example, while authorization is required for use of dibutyl phthalate (CASRN 84-74-2) in the EU and Republic of Korea, it is approved for use in food-contact plastics in the EU, US, and Japan. This regulatory inconsistency needs to be properly addressed, for example, through closer collaboration among regulatory domains and agencies. ${ }^{96}$

In this study, the production volume is used as a rough surrogate to reflect exposure potential of a chemical. More realistic exposure estimates for a large set of chemicals are currently not possible to make due to a lack of substance- and use-specific information in the public domain. ${ }^{37,97}$ Substancespecific information is particularly lacking for metal-containing organic substances (30\% of the identified substances) and surfactants, as measurements or estimations of substance properties such as partition and diffusion coefficients remain difficult to do or make for these substances. ${ }^{98,99}$ Future work may focus on, for example, developing new approaches for measuring or estimating partition and diffusion coefficients of all substances and generating and releasing detailed use information such as used volumes, product contents, and release potential concerning individual uses. ${ }^{100}$

The screening of regulations in this study reveals some gaps and inconsistencies; this effort is not comprehensive. This is partially due to (1) a lack of easy information access to 
regulations in many parts of the world, (2) a common listing of groups of substances using generic descriptions without specifying individual substances, and (3) general challenges in identifying all relevant substances by manual list curation or manual search. An example of (2) is that the listing of PFOArelated compounds under the Stockholm Convention refers to "any substances that degrade to PFOA, including any substances (including salts and polymers) having a linear or branched perfluoroheptyl group with the moiety $(\mathrm{C} 7 \mathrm{~F} 15) \mathrm{C}$ as one of the structural elements"; the recognition of individual substances such as "alkyl iodides, $\mathrm{C}_{10-12}, \gamma, \omega$-perfluoro" (CASRN 6839033-0) as PFOA-related compounds currently requires expert knowledge. Therefore, facilitating information access to regulations around the world, for example, through a global virtual knowledge base and further developing cheminformatics tools that help identify whether a substance is listed based on its molecular structure can be highly useful. Specifically, data engines that are capable of identifying all related CASRNs, chemical names, and structures and of indexing them based on $\mathrm{InChI}($ Keys $)$ could prove to be beneficial in this work.

\section{POSSIBLE WAYS FORWARD}

This study identifies over 10'000 plastic-related substances and details several critical knowledge and data gaps, particularly in terms of substance- and use-specific information. This scale of chemicals to be addressed may be much greater than previously expected according to previously published assessments. Here, we highlight the following overarching areas that warrant concerted international efforts, in order to address these chemicals efficiently and effectively. This study can also serve as a starting point of immediate action, for example, by prioritizing substances of potential concern and the critical knowledge and data gaps identified above. Furthermore, while this study focuses on plastic monomers, additives, and processing aids, many of the lessons learned may also be used to enhance the general sound management of chemicals.

5.1. Establishing a Centralized Knowledge Base. Information on chemicals is scattered throughout the public domain, resulting in numerous difficulties in understanding the presence of chemicals in plastics and other products and their properties and risks, as illustrated above. It may be worthwhile to consider establishing an open and transparent centralized knowledge base of chemicals in products with inputs and support from all relevant stakeholders along the supply chains (e.g., chemical and material producers, product designers, retailers, and waste managers). It can contribute to a better overview of relevant chemicals and related information and thus provide a basis for prioritization of future work, for example, based on production volumes and/or hazardous properties.

Such a knowledge base could build on this work and other existing public databases (e.g., PubChem, SciFinder, OECD eChemPortal, CAS Common Chemistry, and USEPA CompTox Chemicals Dashboard) and industrial transparency initiatives [for example, Global Automotive Declarable Substance List (GADSL), the HolyGrail project led by P\&G]. ${ }^{70}$ The costs of establishing and maintaining such a large database can be perceived an impediment, as well as questions around data ownership (e.g., CASRNs are intellectual properties of the Chemical Abstracts Service and may require licensing for publication). ${ }^{101}$ Options to navigate these barriers to access may include cofunding such an initiative through public-private partnerships, as a part of companies' corporate social responsibility and commitments to the human right to science, and harmonizing information exchange standards across the existing major databases to allow easy retrieval and compilation of information at one central place. ${ }^{102-104}$ Regardless, transparency, independence, and open accessibility are crucial for such a knowledge base, and strong leadership through national and/or international governmental organizations (e.g., United Nations Environment Programme, OECD, ECHA) is needed for setting it up.

5.2. Ensuring Transition to a Safe and Sustainable Circular Plastic Economy. A vast number of diverse substances are potentially used in the manufacture of plastics, with over $20 \%$ being substances of potential concern. Meanwhile, current regulations, scientific and regulatory monitoring efforts, and industry initiatives lag far behind the introduction of these substances to the market, to ensure clean, safe, and highquality virgin and recycled plastics. For example, the current European chemicals regulations mostly focus on single substances and/or certain industrial sectors (e.g., plastics for food-contact purposes, in toys, in electrical and electronic equipment, and in automotive applications). ${ }^{105-107}$ Similarly, current industrial circular economy initiatives focus primarily on the material level (e.g., using the same polymer for multilayer plastics to increase recyclability), with limited attention paid to the chemicals therein. ${ }^{108-113}$

To ensure the transition toward a safe and sustainable circular plastic economy, concerted efforts by all stakeholders are needed in at least the following areas: ${ }^{114}$ developing standardized approaches to assessing the sustainable circularity of plastics and chemicals therein; avoiding hazardous substances and embedding sustainable circularity in the design phase of plastic polymers, additives, processing aids, and value chains; fostering greater transparency throughout value chains including waste management and broadening monitoring efforts; developing and sharing knowledge on creating sustainable circularity of plastics and chemicals therein; and fostering innovative and chemical management enabling business models and practices.

The information compiled in this study may help initial screenings of safer alternatives in specific applications, followed by more detailed alternative assessments. ${ }^{15}$ Note that the indispensability or "essential" use of a substance for a specific function/performance (in a specific application) may also be evaluated first to phase out those uses that are nonessential and thus reduce the numbers of existing chemicals on the market and their uses to be assessed and transitioned. ${ }^{114-118}$

5.3. Expanding and Harmonizing Regulatory Efforts. Current chemical regulation does not ensure global sustainable management of chemicals for several reasons: (a) not all substances of potential concern are listed under relevant international or regional regulations (Section 3.3); (b) substance-by-substance regulations may not protect against regrettable substitutions; ${ }^{119,120}$ (c) regional regulations might lead to shifting chemical pollution elsewhere; ${ }^{121}$ and (d) negative externalities (e.g., monitoring costs, potential cleanup costs, public health damages, and impaired ecosystem services) of chemicals throughout their life cyles are not fully addressed by current regulations. ${ }^{122,123}$ Potential ways forward include (a) increasing the number of substances under regulatory scrutiny to cover all substances of potential concern; ${ }^{124}$ (b) focusing on group- or class-based regulatory approaches to avoid substituting one hazardous substance with another hazardous one in the same group or class; ${ }^{125,126}$ (c) fostering cooperation among regulators from different fields ${ }^{96,127}$ and regions ${ }^{128,129}$ to ensure consistent measures and avoid shifting pollution to countries 
with less stringent regulations; and (d) complementing current regulation with market-based policy instruments to internalize externalities and incentivize true innovation and pioneers. ${ }^{114}$ Examples of market-based policy instruments include tradable use permits or a Pigouvian tax, where the raised governmental revenue is used to finance cleanup or chemical-related public health costs and helps to create financial incentives for avoiding the use of hazardous or unnecessary chemicals. ${ }^{122,123}$ Overall, concerted efforts from industry, civil society organizations, the scientific community, regulatory agencies, and other policymakers are urgently needed to ensure sustainable chemicals management in the future.

\section{ASSOCIATED CONTENT}

\section{SI Supporting Information}

The Supporting Information is available free of charge at https://pubs.acs.org/doi/10.1021/acs.est.1c00976.

Excel file with large tables presenting data sources and retrieval, keywords for the categorization, and overviews of all substances and substances of potential concern (ZIP)

PDF file presenting details on methods, additional results, and additional discussion on chemicals on the global market (PDF)

\section{AUTHOR INFORMATION}

\section{Corresponding Authors}

Helene Wiesinger - Chair of Ecological Systems Design, Institute of Environmental Engineering, ETH Zürich, 8093 Zürich, Switzerland; 이이.org/0000-0003-4154-5907; Email: wiesinger@ifu.baug.ethz.ch

Zhanyun Wang - Chair of Ecological Systems Design, Institute of Environmental Engineering, ETH Zürich, 8093 Zürich, Switzerland; 이이. orcid.org/0000-0001-9914-7659; Email: Zhanyun.wang@ifu.baug.ethz.ch

\section{Author}

Stefanie Hellweg - Chair of Ecological Systems Design, Institute of Environmental Engineering, ETH Zürich, 8093 Zürich, Switzerland

Complete contact information is available at:

https://pubs.acs.org/10.1021/acs.est.1c00976

\section{Notes}

The authors declare no competing financial interest.

\section{ACKNOWLEDGMENTS}

We gratefully acknowledge the financial support of the Swiss Federal Office for the Environment (8T20/17.0103.PJ), the Swiss Federal Office of Public Health (18.000809), and the Canton of Zurich's Office for Waste, Water, Energy and Air (85P-1454). We thank Magdalena Klotz and Melanie Haupt (ETH Zurich) for their valuable feedback and discussion, Joanna Houska (EAWAG/EPFL, former ETH Zurich) for the initial compilation of various relevant data sources and feedback on the final manuscript, and Christopher Oberschelp (ETH Zurich) for his valuable input regarding confidence assessment of sources. We further thank the members of the Clean Cycle Advisory Board for their feedback and support, the anonymous reviewers for their comments and suggestions to improve the manuscript, and Naomi Lubick for her technical editorial support.

\section{REFERENCES}

(1) PlasticsEurope. Plastics-the Facts 2018. https://www. plasticseurope.org/de/resources/publications/670-plastics-facts-2018 (accessed May 8, 2021).

(2) Organisation for Economic Cooperation and Development (OECD). Expert Group on Polymer Definition. OECD Definition of Polymer. https://www.oecd.org/env/ehs/oecddefinitionofpolymer. htm (accessed May 8, 2021).

(3) Organisation for Economic Cooperation and Development (OECD). Emission Scenario Document on Plastics Additives; Organisation for Economic Cooperation and Development (OECD): Paris, 2009. http://www.oecd.org/officialdocuments/ displaydocument $/$ cote $=\mathrm{env} / \mathrm{jm} / \mathrm{mono}(2004) 8 / \mathrm{rev} 1 \&$ doclanguage $=$ en (accessed May 8, 2021).

(4) Baur, E.; Osswald, T. A.; Rudolph, N. Plastics Handbook; Carl Hanser Verlag GmbH \& Co. KG: München, 2019.

(5) Rodriguez, F. Plastic. Encyclopæedia Britannica; Encyclopædia Britannica Inc., 2020. https://www.britannica.com/science/plastic (accessed May 8, 2021).

(6) Andrews, S. M. Additives. Encyclopedia of Polymer Science and Technology; Wiley, 2010.

(7) Zweifel, H.; Amos, S. E. Plastics Additives Handbook, 6th ed.; Hanser: München, 2009.

(8) Fink, J. K. A Concise Introduction to Additives for Thermoplastic Polymers; John Wiley \& Sons, Inc.: Hoboken, NJ, USA, 2009.

(9) Kaiser, W. Kunststoffchemie Für Ingenieure, 3rd ed.; Carl Hanser Verlag GmbH \& Co. KG: München, 2011.

(10) Geueke, B. Dossier-Non-Intentionally Added Substances (NIAS): Zürich, 2013. https://www.foodpackagingforum.org/fpf2016/wp-content/uploads/2015/11/FPF_Dossier03_NIAS.pdf (accessed May 8, 2021).

(11) Geueke, B. Dossier-Non-intenionally Added Substances (NIAS), 2nd ed.: Zürich, 2018. https://www.foodpackagingforum.org/foodpackaging-health/non-intentionally-added-substances-nias (accessed May 8, 2021).

(12) European Chemicals Agency (ECHA). Plastic Additives Initiative. https://echa.europa.eu/et/plastic-additives-initiative (accessed August 27, 2019).

(13) Groh, K. J.; Backhaus, T.; Carney-Almroth, B.; Geueke, B.; Inostroza, P. A.; Lennquist, A.; Leslie, H. A.; Maffini, M.; Slunge, D.; Trasande, L.; Warhurst, A. M.; Muncke, J. Overview of Known Plastic Packaging-Associated Chemicals and Their Hazards. Sci. Total Environ. 2019, 651, 3253-3268.

(14) Zimmermann, L.; Dierkes, G.; Ternes, T. A.; Völker, C.; Wagner, M. Benchmarking the in Vitro Toxicity and Chemical Composition of Plastic Consumer Products. Environ. Sci. Technol. 2019, 53, 1146711477.

(15) Rudel, R. A.; Camann, D. E.; Spengler, J. D.; Korn, L. R.; Brody, J. G. Phthalates, Alkylphenols, Pesticides, Polybrominated Diphenyl Ethers, and Other Endocrine-Disrupting Compounds in Indoor Air and Dust. Environ. Sci. Technol. 2003, 37, 4543-4553.

(16) Lunderberg, D. M.; Kristensen, K.; Liu, Y.; Misztal, P. K.; Tian, Y.; Arata, C.; Wernis, R.; Kreisberg, N.; Nazaroff, W. W.; Goldstein, A. $\mathrm{H}$. Characterizing Airborne Phthalate Concentrations and Dynamics in a Normally Occupied Residence. Environ. Sci. Technol. 2019, 53, 73377346.

(17) Lucattini, L.; Poma, G.; Covaci, A.; de Boer, J.; Lamoree, M. H.; Leonards, P. E. G. A Review of Semi-Volatile Organic Compounds (SVOCs) in the Indoor Environment: Occurrence in Consumer Products, Indoor Air and Dust. Chemosphere 2018, 201, 466-482.

(18) Kwan, C. S.; Takada, H. Release of Additives and Monomers from Plastic Wastes. In Hazardous Chemicals Associated with Plastics in the Marine Environment. The Handbook of Environmental Chemistry; Takada, H., Karapanagioti, H. K., Eds.; Springer International Publishing: Cham, 2016; pp 51-70.

(19) Koelmans, A. A.; Besseling, E.; Foekema, E. M. Leaching of Plastic Additives to Marine Organisms. Environ. Pollut. 2014, 187, 4954. 
(20) Karapanagioti, H. K.; Takada, H. Hazardous Chemicals Associated with Plastics in the Marine Environment. In The Handbook of Environmental Chemistry; Takada, H., Karapanagioti, H. K., Eds.; Springer International Publishing: Cham, 2019; Vol. 78.

(21) Tang, Z.; Zhang, L.; Huang, Q.; Yang, Y.; Nie, Z.; Cheng, J.; Yang, J.; Wang, Y.; Chai, M. Contamination and Risk of Heavy Metals in Soils and Sediments from a Typical Plastic Waste Recycling Area in North China. Ecotoxicol. Environ. Saf. 2015, 122, 343-351.

(22) Tang, Z.; Huang, Q.; Yang, Y.; Nie, Z.; Cheng, J.; Yang, J.; Wang, Y.; Chai, M. Polybrominated Diphenyl Ethers (PBDEs) and Heavy Metals in Road Dusts from a Plastic Waste Recycling Area in North China: Implications for Human Health. Environ. Sci. Pollut. Res. 2016, 23, 625-637.

(23) He, Z.; Li, G.; Chen, J.; Huang, Y.; An, T.; Zhang, C. Pollution Characteristics and Health Risk Assessment of Volatile Organic Compounds Emitted from Different Plastic Solid Waste Recycling Workshops. Environ. Int. 2015, 77, 85-94.

(24) Koch, H. M.; Calafat, A. M. Human Body Burdens of Chemicals Used in Plastic Manufacture. Philos. Trans. R. Soc., B 2009, 364, 20632078.

(25) Meeker, J. D.; Sathyanarayana, S.; Swan, S. H. Phthalates and Other Additives in Plastics: Human Exposure and Associated Health Outcomes. Philos. Trans. R. Soc., B 2009, 364, 2097-2113.

(26) Turner, A. Black Plastics: Linear and Circular Economies, Hazardous Additives and Marine Pollution. Environ. Int. 2018, 117, 308-318.

(27) Day, M.; Cooney, J. D.; MacKinnon, M. Degradation of Contaminated Plastics: A Kinetic Study. Polym. Degrad. Stab. 1995, 48, 341-349.

(28) Hunt, A.; Dale, N.; George, F. World Health Organization (WHO) Regional Office for Europe. Circular Economy and Health: Opportunities and Risk: Copenhagen, 2018. https://www.euro.who. int/en/publications/abstracts/circular-economy-and-healthopportunities-and-risks-2018 (accessed May 8, 2021).

(29) Leslie, H. A.; Leonards, P. E. G.; Brandsma, S. H.; de Boer, J.; Jonkers, N. Propelling Plastics into the Circular Economy - Weeding out the Toxics First. Environ. Int. 2016, 94, 230-234.

(30) Eriksen, M. K.; Pivnenko, K.; Olsson, M. E.; Astrup, T. F. Contamination in Plastic Recycling: Influence of Metals on the Quality of Reprocessed Plastic. Waste Manag. 2018, 79, 595-606.

(31) Hansen, E.; Nilsson, N. H.; Lithner, D.; Lassen, C. Hazardous Substances in Plastic Materials; COWI, Danish Technological Institute: Vejle, Denmark, 2013. https://www.byggemiljo.no/wp-content/ uploads/2014/10/72 ta3017.pdf (accessed May 8, 2021).

(32) Rossi, M.; Blake, A.; Clean Production Action. Plastics Scorecard; Clean Production Action: Somerville, 2014. https://www. cleanproduction.org/resources/entry/plastics-scorecard-resource (accessed May 8, 2021).

(33) Stenmarck, Å.; Belleza, E. L.; Fråne, A.; Busch, N.; Larsen, Å.; Wahlström, M. Hazardous Substances in Plastics-Ways to Increase Recycling; Swedish Environmental Research Institute IVL, Nordic Council of Ministers: Stockholm, Sweden, 2017.

(34) Hahladakis, J. N.; Velis, C. A.; Weber, R.; Iacovidou, E.; Purnell, P. An Overview of Chemical Additives Present in Plastics: Migration, Release, Fate and Environmental Impact during Their Use, Disposal and Recycling. J. Hazard. Mater. 2018, 344, 179-199.

(35) Lithner, D.; Larsson, Å.; Dave, G. Environmental and Health Hazard Ranking and Assessment of Plastic Polymers Based on Chemical Composition. Sci. Total Environ. 2011, 409, 3309-3324.

(36) Hollender, J.; Schymanski, E. L.; Singer, H. P.; Ferguson, P. L. Nontarget Screening with High Resolution Mass Spectrometry in the Environment: Ready to Go? Environ. Sci. Technol. 2017, 51, 1150511512 .

(37) Schymanski, E. L.; Singer, H. P.; Slobodnik, J.; Ipolyi, I. M.; Oswald, P.; Krauss, M.; Schulze, T.; Haglund, P.; Letzel, T.; Grosse, S.; Thomaidis, N. S.; Bletsou, A.; Zwiener, C.; Ibáñez, M.; Portolés, T.; de Boer, R.; Reid, M. J.; Onghena, M.; Kunkel, U.; Schulz, W.; Guillon, A.; Noyon, N.; Leroy, G.; Bados, P.; Bogialli, S.; Stipaničev, D.; Rostkowski, P.; Hollender, J. Non-Target Screening with High-
Resolution Mass Spectrometry: Critical Review Using a Collaborative Trial on Water Analysis. Anal. Bioanal. Chem. 2015, 407, 6237-6255.

(38) Martínez-Bueno, M. J.; Gómez Ramos, M. J.; Bauer, A.; Fernández-Alba, A. R. An Overview of Non-Targeted Screening Strategies Based on High Resolution Accurate Mass Spectrometry for the Identification of Migrants Coming from Plastic Food Packaging Materials. TrAC, Trends Anal. Chem. 2019, 110, 191-203.

(39) Onghena, M.; van Hoeck, E.; Vervliet, P.; Scippo, M. L.; Simon, C.; van Loco, J.; Covaci, A. Development and Application of a NonTargeted Extraction Method for the Analysis of Migrating Compounds from Plastic Baby Bottles by GC-MS. Food Addit. Contam., Part A 2014, 31, 2090-2102.

(40) Vera, P.; Canellas, E.; Nerín, C. Identification of Non Volatile Migrant Compounds and NIAS in Polypropylene Films Used as Food Packaging Characterized by UPLC-MS/QTOF. Talanta 2018, 188, $750-762$.

(41) Nerin, C.; Alfaro, P.; Aznar, M.; Domeño, C. The Challenge of Identifying Non-Intentionally Added Substances from Food Packaging Materials: A Review. Anal. Chim. Acta 2013, 775, 14-24.

(42) Schymanski, E. L.; Williams, A. J. Open Science for Identifying "Known Unknown" Chemicals. Environ. Sci. Technol. 2017, 51, 53575359.

(43) Lithner, D. Environmental and Health Hazards of Chemicals in Plastic Polymers and Products. Ph.D. Thesis, University of Gothenburg, Göteborg, 2011. http://hdl.handle.net/2077/24978 (accessed May 8, 2021).

(44) Wagner, S.; Schlummer, M. Legacy Additives in a Circular Economy of Plastics: Current Dilemma, Policy Analysis, and Emerging Countermeasures. Resour., Conserv. Recycl. 2020, 158, 104800.

(45) Chemical Abstract Service (CAS). Check Digit Verification. https://www.cas.org/support/documentation/chemical-substances/ checkdig (accessed May 8, 2021).

(46) American Chemical Society (ACS). SciFinder. https://scifinder. cas.org/ (accessed April 15, 2020).

(47) United States Environmental Protection Agency (EPA). CompTox Chemicals Dashboard. https://comptox.epa.gov/ dashboard (accessed April 2, 2020).

(48) International Agency for Research on Cancer (IARC). Monographs on the Identification of Carcinogenic Hazards to Humans-List of Classifications. https://monographs.iarc.fr/list-ofclassifications/ (accessed January 10, 2020).

(49) Safe Work Australia (SWA). Hazardous Chemical Information System (HCIS). http://hcis.safeworkaustralia.gov.au/ HazardousChemical (accessed April 2, 2020).

(50) Japanese National Institute of Technology and Evaluation (nite). GHS Classification Results. https://www.nite.go.jp/chem/english/ ghs/ghs download.html (accessed January 10, 2020).

(51) European Chemicals Agency (ECHA). Classification and Labelling (C\&L) Inventory. https://echa.europa.eu/information-onchemicals/cl-inventory-database (accessed February 4, 2020).

(52) European Chemicals Agency (ECHA). Authorisation List. https://echa.europa.eu/authorisation-list (accessed April 2, 2020).

(53) European Chemicals Agency (ECHA). Candidate List of substances of very high concern for Authorisation. https://echa. europa.eu/candidate-list-table (accessed April 2, 2020).

(54) European Chemicals Agency (ECHA). PBT assessment list. https://echa.europa.eu/pbt (accessed December 22, 2020).

(55) European Chemicals Agency (ECHA). Endocrine disruptor assessment list. https://echa.europa.eu/de/ed-assessment (accessed April 2, 2020).

(56) European Chemicals Agency (ECHA). Advanced Search for Chemicals. https://echa.europa.eu/advanced-search-for-chemicals (accessed December 9, 2019).

(57) Organisation for Economic Cooperation and Development (OECD). Classification Search on eChemPortal. https://www. echemportal.org/echemportal/ghs-search (accessed August 12, 2020).

(58) Organisation for Economic Cooperation and Development (OECD). OECD Existing Chemicals Database-High Production 
Volume (HPV) chemicals. https://hpvchemicals.oecd.org/UI/Search. aspx (accessed January 10, 2020).

(59) United States Environmental Protection Agency (EPA). Chemical Data Reporting (CDR)-2016 CDR Data. https://www. epa.gov/chemical-data-reporting/access-cdr-data\#2016 (accessed February 1, 2019).

(60) European Chemicals Agency (ECHA). Registered Substances. https://echa.europa.eu/information-on-chemicals/registeredsubstances (accessed January 29, 2020).

(61) norden. SPIN-Substances in Preparations in Nordic Countries. http://spin2000.net/ (accessed December 16, 2019).

(62) Wang, Z.; Walker, G. W.; Muir, D. C. G.; Nagatani-Yoshida, K. Toward a Global Understanding of Chemical Pollution: A First Comprehensive Analysis of National and Regional Chemical Inventories. Environ. Sci. Technol. 2020, 54, 2575-2584.

(63) Pelzl, B.; Wolf, R.; Kaul, B. L. Plastics, Additives. Ullmann's Encyclopedia of Industrial Chemistry; Wiley-VCH Verlag $\mathrm{GmbH} \& \mathrm{Co}$. KGaA: Weinheim, Germany, 2018; pp 1-57.

(64) Kawecki, D.; Scheeder, P. R. W.; Nowack, B. Probabilistic Material Flow Analysis of Seven Commodity Plastics in Europe. Environ. Sci. Technol. 2018, 52, 9874-9888.

(65) Klotz, M.; Haupt, M.; Hellweg, S. A High-Resolution Dataset on the Plastic Material Flows in Switzerland in 2017, 2021. (Unpublished Research). https://esd.ifu.ethz.ch/research/research-and-theses/ clean-cycle.html (accessed May 8, 2021).

(66) Bolinius, D. J.; Sobek, A.; Löf, M. F.; Undeman, E. Evaluating the Consumption of Chemical Products and Articles as Proxies for Diffuse Emissions to the Environment. Environ. Sci.: Processes Impacts 2018, 20, 1427-1440.

(67) Directorate-General for Environment (DG Environment); European Commission; Risk \& Policy Analysts (RPA); Milieu Ltd; RIVM; Oekopol; Reihlen, A. Study for the Strategy for a Non-Toxic Environment of the 7th EAP-Sub-Study b: Chemicals in Products and Non-Toxic Material Cycles: Brussels, Belgium, 2017. https://ec. europa.eu/environment/chemicals/non-toxic/pdf/Substudybarticlesnon-toxicmaterialcyclesNTEfinal.pdf (accessed May 8, 2021).

(68) European Commission. Sustainable products initiative. https:// ec.europa.eu/info/law/better-regulation/have-your-say/initiatives/ 12567-Sustainable-Products-Initiative (accessed May 8, 2021).

(69) European Chemicals Agency (ECHA). SCIP-Substances of Concern In articles as such or in complex objects (Products). https:// echa.europa.eu/scip (accessed May 8, 2021).

(70) Ellen MacArthur Foundation. HolyGrail: tagging packaging for accurate sorting and high-quality recycling. https://www. newplasticseconomy.org/assets/doc/Holy-Grail.pdf (accessed May 8, 2021).

(71) Kogg, B.; Thidell, A. Chemicals in Products-An Overview of Systems for Providing Information Regarding Chemicals in Products and of Stakeholders' Needs for Such Information, Lund, 2010; United Nations Environment Programme (UNEP): Lund, 2010. https://www.unep. org/resources/other-evaluation-reportsdocuments/chemicalsproducts-cip-programme (accessed May 8, 2021).

(72) United Nations Environment Programme (UNEP); Strategic Approach to International Chemicals Management (SAICM); InterOrganization Programme for the sound management of chemicals (IOMC). The Chemicals in Products (CiP) Programme; United Nations Environment Programme (UNEP): Geneva, 2015. https://www.unep. $\mathrm{org} /$ resources/other-evaluation-reportsdocuments/chemicalsproducts-cip-programme (accessed May 8, 2021).

(73) Heller, S. R.; McNaught, A.; Pletnev, I.; Stein, S.; Tchekhovskoi, D. InChI, the IUPAC International Chemical Identifier. J. Cheminf. 2015, 7, 23.

(74) Eurostat. Statistics explained. NACE background. https://ec. europa.eu/eurostat/statistics-explained/index.php?title=NACE_ background (accessed May 8, 2021).

(75) United States Census Bureau. North American Industry Classification System. https://www.census.gov/naics/ (accessed May $8,2021)$.
(76) United Nations Statistics Division (UNSD). International Standard Industrial Classification (ISIC). https://unstats.un.org/ unsd/classifications/Econ/ISIC.cshtml (accessed May 8, 2021).

(77) Varnek, A.; Baskin, I. Machine Learning Methods for Property Prediction in Chemoinformatics: Quo Vadis? J. Chem. Inf. Model. 2012, $52,1413-1437$.

(78) Mitchell, J. B. O. Machine Learning Methods in Chemoinformatics. Wiley Interdiscip. Rev.: Comput. Mol. Sci. 2014, 4, 468-481.

(79) Linguamatics-An iQVIA company. Chemical Search and natural language processing. https://www.linguamatics.com/ products/chemistry (accessed May 8, 2021).

(80) Rugard, M.; Coumoul, X.; Carvaillo, J.-C.; Barouki, R.; Audouze, K. Deciphering Adverse Outcome Pathway Network Linked to Bisphenol F Using Text Mining and Systems Toxicology Approaches. Toxicol. Sci. 2020, 173, 32-40.

(81) ChemAxon. ChemLocator. https://chemaxon.com/products/ chemlocator (accessed May 8, 2021).

(82) Horodytska, O.; Cabanes, A.; Fullana, A. Non-Intentionally Added Substances (NIAS) in Recycled Plastics. Chemosphere 2020, $251,126373$.

(83) Kröhnke, C.; Schacker, O.; Zäh, M. Antioxidants. Ullmann's Encyclopedia of Industrial Chemistry; Wiley-VCH Verlag GmbH \& Co. KGaA: Weinheim, Germany, 2015.

(84) Dexter, M.; Thomas, R. W.; King, R. E. Antioxidants. Encyclopedia of Polymer Science and Technology; John Wiley \& Sons, Inc.: Hoboken, NJ, USA, 2002.

(85) Groh, K. J.; Geueke, B.; Martin, O.; Maffini, M.; Muncke, J. Overview of Intentionally Used Food Contact Chemicals and Their Hazards. Environ. Int. 2021, 150, 106225.

(86) IHS Markit. Plastic Additives, 2017. https://ihsmarkit.com/ products/chemical-plastics-additives-scup.html (accessed May 8, 2021).

(87) IHS Markit. Plasticizers-Chemical Economics Handbook, 2018. https://ihsmarkit.com/products/plasticizers-chemicaleconomics-handbook.html (accessed May 8, 2021).

(88) Bolgar, M.; Hubball, J.; Groeger, J.; Meronek, S. Handbook for the Chemical Analysis of Plastic and Polymer Additives, 2nd ed.; CRC Press: Boca Raton, 2015.

(89) Dionisio, K. L.; Frame, A. M.; Goldsmith, M.-R.; Wambaugh, J. F.; Liddell, A.; Cathey, T.; Smith, D.; Vail, J.; Ernstoff, A. S.; Fantke, P.; Jolliet, O.; Judson, R. S. Exploring Consumer Exposure Pathways and Patterns of Use for Chemicals in the Environment. Toxicol. Rep. 2015, 2, 228-237.

(90) Sheftel, V. O. Indirect Food Additives and Polymers, 1st ed.; CRC Press: Boca Raton, 2000.

(91) Godwin, A.; ExxonMobil Chemical Company. Uses of Phthalates and Other Plasticizers, 2010; pp 1-17. https://www.cpsc.gov/s3fspublic/godwin.pdf (accessed May 8, 2021).

(92) Simpson, S. S.; Adams, N.; Brugman, C. M.; Conners, T. J. Detecting Novel and Emerging Drug Terms Using Natural Language Processing: A Social Media Corpus Study. JMIR Public Heal. Surveill. 2018, 4, No. e2.

(93) Bier, V. M.; Lin, S.-W. Should the Model for Risk-Informed Regulation Be Game Theory Rather than Decision Theory? Risk Anal. 2013, 33, 281-291.

(94) Stafford, S. L. Self-Policing in a Targeted Enforcement Regime. South. Econ. J. 2008, 74, 934-951.

(95) European Chemicals Agency (ECHA). PBT assessment. https:// echa.europa.eu/understanding-pbt-assessment (accessed May 8, 2021).

(96) European Chemicals Agency (ECHA); European Food Safety Authority (EFSA). In Support of the EU Chemicals Strategy for Sustainability: One Substance-One Assessment, 2020. https://www. efsa.europa.eu/it/corporate/pub/osoa (accessed May 8, 2021).

(97) Johnson, B. L.; Vermeire, T. G. Risk Assessment of Chemicals: An Introduction, 2nd ed.; Van Leeuwen, C. J., Vermeire, T. G., Eds.; Springer: Dordrecht, 2009.

(98) Organisation for Economic Cooperation and Development (OECD). OECD Guidelines for the Testing of Chemicals; Organisation 
for Economic Cooperation and Development (OECD), 2020. https:// www.oecd-ilibrary.org/environment/oecd-guidelines-for-the-testingof-chemicals 72d77764-en (accessed May 8, 2021).

(99) Ambure, P.; Cordeiro, M. N. D. S. Importance of Data Curation in QSAR Studies Especially While Modeling Large-Size Datasets. In Ecotoxicological QSARs; Roy, K., Ed.; Springer Nature: New York, 2020; pp 97-109.

(100) norman; Swedish Chemicals Agency (KEMI). Exposure Index for Industrial Chemicals. 1-6. https://www.norman-network.com/ sites/default/files/files/Events/2016/WG1_Paris/NORMAN exposure_index_biocides_27Jun2016_Ruedel_toWG-1.pdf (accessed May 8, 2021).

(101) Chemical Abstract Service (CAS). CAS Registry Number (CAS RN) Verified Partner Program. https://www.cas.org/support/ documentation/chemical-substances/cas-rn-verified-partner-program (accessed May 8, 2021).

(102) Secretariat of the Basel Rotterdam and Stockholm Convention. Resources for developers. http://www.brsmeas.org/Implementation/ KnowledgeManagementandOutreach/Clearinghousemechanism/ Resourcesfordevelopers/tabid/5801/language/en-US/Default.aspx (accessed May 8, 2021).

(103) United Nations Information Portal on Multilateral Environmental Agreements (InforMEA). Resources for Developers. https:// www.informea.org/en/about/api (accessed May 8, 2021).

(104) OData-The Protocol for REST APIs. OData-the best way to REST. https://www.odata.org/ (accessed May 8, 2021).

(105) European Parliament; Council of the European Union. Council Directive 2009/48/EC on the Safety of Toys; European Parliament: Brussels, 2009; Vol. L48. http://data.europa.eu/eli/dir/2009/48/ 2019-11-18 (accessed May 8, 2021).

(106) European Parliament; Council of the European Union. Council Directive 2011/65/EU on the Restriction of the Use of Certain Hazardous Substances (RoHS) in Electrical and Electronic Equipment (EEE); European Parliament: Brussels, 2011; Vol. L174. http://data.europa. eu/eli/dir/2011/65/2021-04-01 (accessed May 8, 2021).

(107) European Parliament; Council of the European Union. Council Regulation (EC) 1935/2004 on Materials and Articles Intended to Come into Contact with Food; European Parliament: Brussels, Belgium, 2004; Vol. 2004R1935, p Regulation (EC) No 1935/200. http://data.europa. eu/eli/reg/2004/1935/2021-03-27 (accessed May 8, 2021).

(108) Unilever. Rethinking Plastic Packaging-towards a Circular Economy; Unilever, 2019. https://www.unilever.com/sustainableliving/reducing-environmental-impact/waste-and-packaging/ rethinking-plastic-packaging/\#244-421040 (accessed May 8, 2021).

(109) Ellen MacArthur Foundation, World Economic Forum, McKinsey \& Company. The New Plastics Economy: Rethinking the Future of Plastics, 2016. https://www.ellenmacarthurfoundation.org/ assets/downloads/The-New-Plastics-Economy-Rethinking-theFuture-of-Plastics.pdf (accessed May 8, 2021).

(110) Alliance to End Plastic Waste. https://endplasticwaste.org/ about/ (accessed May 8, 2021).

(111) VinylPlus. The European PVC Industry's Experience in Replacing Lead and Cadmium-Based Stabilisers: Brussels, Belgium, 2014. https://www.stabilisers.eu/wp-content/uploads/2015/11/ VinylPlus_Contribution-Cefic_Eu-Industry.pdf (accessed May 8, 2021).

(112) Geueke, B.; Groh, K.; Muncke, J. Food Packaging in the Circular Economy: Overview of Chemical Safety Aspects for Commonly Used Materials. J. Cleaner Prod. 2018, 193, 491-505.

(113) European Environment Agency (EEA). Designing Safe and Sustainable Products Requires a New Approach for Chemicals Key Messages; European Environment Agency (EEA): Copenhagen, 2020. https://www.eea.europa.eu/themes/human/chemicals/deliveringproducts-that-are-safe (accessed May 8, 2021).

(114) Wang, Z.; Hellweg, S. First Steps toward Sustainable Circular Uses of Chemicals: Advancing the Assessment and Management Paradigm. ACS Sustainable Chem. Eng. 2021, 9, 6939.

(115) Organisation for Economic Cooperation and Development (OECD). Guidance on Key Considerations for the Identification and
Selection of Safer Chemical Alternatives. Series on Risk Management No.60; Organisation for Economic Cooperation and Development (OECD): Paris, 2021. https://www.oecd.org/chemicalsafety/riskmanagement/guidance-on-key-considerations-for-the-identificationand-selection-of-safer-chemical-alternatives.pdf (accessed May 8, 2021).

(116) European PET Bottle Platform (EPBP). Design for Recycling Guidelines for PET bottles. https://www.epbp.org/design-guidelines (accessed May 8, 2021).

(117) Cousins, I. T.; Goldenman, G.; Herzke, D.; Lohmann, R.; Miller, M.; Ng, C. A.; Patton, S.; Scheringer, M.; Trier, X.; Vierke, L.; Wang, Z.; Dewitt, J. C. The Concept of Essential Use for Determining When Uses of PFASs Can Be Phased Out. Environ. Sci.: Processes Impacts 2019, 21, 1803-1815.

(118) Schut, J. H. More Filler, Less Resin: Bag Films Load up to Cut Costs. Plastics Technology, January 12, 2006. https://www.ptonline. $\mathrm{com} /$ articles/more-filler-less-resin-bag-films-load-up-to-cut-costs (accessed May 8, 2021).

(119) Zimmerman, J. B.; Anastas, P. T. Toward Substitution with No Regrets. Science 2015, 347, 1198-1199.

(120) Trasande, L. Exploring Regrettable Substitution: Replacements for Bisphenol A. Lancet Planet. Heal. 2017, 1, e88-e89.

(121) Tang, J. P. Pollution Havens and the Trade in Toxic Chemicals: Evidence from U.S. Trade Flows. Ecol. Econ. 2015, 112, 150-160.

(122) Slunge, D.; Alpizar, F. Market-Based Instruments for Managing Hazardous Chemicals: A Review of the Literature and Future Research Agenda. Sustainability 2019, 11, 4344.

(123) United Nations Environment Programme (UNEP). Global Chemicals Outlook II-from Legacies to Innovative Solutions; United Nations Environment Programme (UNEP): Geneva, 2019. https:// www.unep.org/resources/report/global-chemicals-outlook-ii-legaciesinnovative-solutions (accessed May 8, 2021).

(124) European Chemicals Agency (ECHA). REACH-Authorisation process. https://echa.europa.eu/authorisation-process (accessed May 8, 2021).web

(125) Directorate-General for Environment (DG Environment); European Commission; Risk \& Policy Analysts (RPA); Milieu Ltd.; RIVM; Oekopol; Camboni, M. Study for the Strategy for a Non-toxic Environment of the 7th EAP: Sub-study a: Substitution, Including Grouping of Chemicals \& Measures to Support Substitution: Brussels, Belgium, 2017. https://ec.europa.eu/environment/chemicals/nontoxic/pdf/Sub-studyasubstitutiongroupingNTEfinal.pdf (accessed May 8, 2021).

(126) Jacobs, M. M.; Malloy, T. F.; Tickner, J. A.; Edwards, S. Alternatives Assessment Frameworks: Research Needs for the Informed Substitution of Hazardous Chemicals. Environ. Health Perspect. 2016, 124, 265-280.

(127) van Dijk, J.; Gustavsson, M.; Dekker, S. C.; van Wezel, A. P. Towards "One Substance - One Assessment": An Analysis of EU Chemical Registration and Aquatic Risk Assessment Frameworks. J. Environ. Manage. 2021, 280, 111692.

(128) European Chemicals Agency (ECHA). Factsheet-International Cooperation; European Chemicals Agency (ECHA): Helsinki, 2013. https: / / echa.europa.eu/about-us / partners-and-networks / international-cooperation (accessed May 8, 2021).

(129) United Nations Environment Programme (UNEP). Strategic Approach to International Chemicals Management (SAICM); United Nations Environmental Programme: Geneva, 2006. https://www. unep.org/resources/report/strategic-approach-internationalchemicals-management (accessed May 8, 2021). 